\title{
Effect of Water Deficit Stress on Seedling Biomass and Physio-Chemical Characteristics in Different Species of Wheat Possessing the D Genome
}

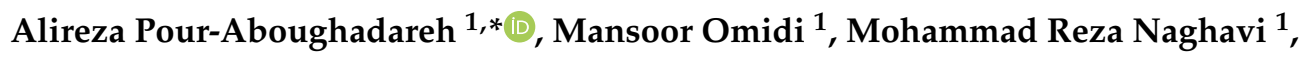 \\ Alireza Etminan ${ }^{2}$, Ali Ashraf Mehrabi ${ }^{3}$, Peter Poczai ${ }^{4}$ and Hamid Bayat ${ }^{1}$ \\ 1 Department of Agronomy and Plant Breeding, Agricultural College, University of Tehran, \\ P.O. Box 31587-77871, Karaj, Iran \\ 2 Department of Plant Breeding and Biotechnology, Kermanshah Branch, Islamic Azad University, \\ P.O. Box 6718997551, Kermanshah, Iran \\ 3 Department of Agronomy and Plat Breeding, Ilam University, P.O. Box 69315516, Ilam, Iran \\ 4 Botany Unit, Finnish Museum of Natural History, University of Helsinki, P.O. Box 7, \\ FI-00014 Helsinki, Finland \\ * Correspondence: a.poraboghadareh@gmail.com or a.poraboghadareh@ut.ac.ir
}

Received: 22 July 2019; Accepted: 26 August 2019; Published: 9 September 2019

\begin{abstract}
Wild relatives of wheat serve as an extraordinary source of variability for breeding programs due to their capabilities to respond to various environmental stresses. Here, we investigated some species possessing a D genome (T. aestivum, Ae. tauschii, Ae.crassa and Ae. cylindrica) in terms of relative water content (RWC), stomatal conductance $(G s)$, relative chlorophyll content, initial fluorescence $(F o)$, maximum quantum yield of PSII $(F v / F m)$, maximum primary yield of PSII photochemistry $(F v / F o)$, as well as shoot fresh and dry biomasses under control and water deficit conditions. Our results revealed that water deficit negatively affected all traits; shoot fresh weight, Gs and RWC showed the highest reduction compared to the control condition. Principal component analysis (PCA) identified two PCs that accounted for $53.36 \%$ of the total variation in the water deficit conditions. Correlation analysis and PCA-based biplots showed that stress tolerance index (STI) is significantly associated with $\mathrm{Fv} / \mathrm{Fm}$ and $\mathrm{Fv} / \mathrm{Fo}$ under water stress conditions, suggesting that these are the best parameters to evaluate when screening for tolerant samples at the seedling stage. We identified 19 accessions from Ae. crassa and one from Ae. tauschii as the most tolerant samples. In conclusion, Ae. crassa might provide an ideal genetic resource for drought-tolerant wheat breeds.
\end{abstract}

Keywords: Aegilops species; drought stress; stomatal conductance; photosynthetic capacity; relative water content

\section{Introduction}

Climate change is expected to result in fluctuations in precipitation patterns, including the enhanced severity and accelerated frequency of droughts [1]. Under these circumstances, agricultural production is one of the many sectors already affected by water availability [2]. Indeed, low water availability or water deficit is one of the major environmental factors limiting crop growth and development, productivity and yield performance in many areas across the world [3].

Physiologically, plant growth is controlled by a complex of processes that are adversely affected by water deficit stress. These effects occur through osmotic stress and various biochemical responses in plants, including light absorption and capture, antioxidant activity, stomatal conductance, transpiration, photosynthesis, and respiration [4-7]. Of these processes, photosynthesis is crucial for maintaining plant growth, as this is how the chemical energy consumed by various metabolic processes is 
derived [8]. Water stress can impose limitations or cause damage to the various physiological and biochemical processes related to photosynthesis, including reduction in chlorophyll content, disruption of stomatal conductance, and interference with the rate of net assimilation and photosystem photochemical efficiency parameters. Such damage can inhibit plant growth, ultimately decreasing crop production [9-11].

In the photosynthetic system, photosystem II (PSII) is known to be the most unstable component, as it mainly restricts photochemistry in response to water stress [12]. With progress in understanding crop stress physiology and its related tools, chlorophyll fluorescence (CF) has become known as a useful indicator for investigating stress in plants in vivo [13]. Not only are the effects of water deficit on CF parameters well known and widely reported [13-15], this technique is also a simple, non-destructive and rapid testing method [3,16]. Hence, CF measurement is an efficient approach for screening the stress tolerance of different plant species and genotypes [17]. Earlier reports demonstrated that water deficit stress has unfavorable effects on the efficiency of PSII, as indicated by changes in CF parameters such as initial fluorescence $(F o)$, maximum quantum yield of PSII $(F v / F m)$, maximum primary yield of PSII photochemistry $(F v / F o)$, as well as plant growth and dry matter.

The regulation of leaf stomatal conductance $(G s)$ is another important process related to photosynthesis, and is crucial for both $\mathrm{CO}_{2}$ acquisition and maintenance of water content in leaf tissue $[18,19]$. Under water deficit stress, stomata closure occurs due to atmospheric vapor pressure, decrease in leaf turgor, and signaling pathways [20]. Consequently, stomata closure and prevention of mesophyll conductance cause a reduction in photosynthetic rate under adverse environments [20,21]. Thus, the effects of water stress on photosynthesis are related directly to the stomatal responses for dispersion of gases, which finally alters mesophyll metabolism and photosynthesis $[20,22]$. It has been reported that the methods used for measuring photosynthetic features such as CF parameters and chlorophyll content might also estimate the influence of water stress on growth and yield, since these parameters are significantly associated with the rate of carbon exchange [23-25]. As such, these parameters can be used as reliable parameters to assess the metabolic/energetic imbalance of photosynthesis and grain yield across various plant genotypes under water deficit [24,26].

Bread wheat (Triticum aestivum L.) is an important cereal crop, providing $21 \%$ of the world's protein intake and $19 \%$ of the world's food energy [27]. Due to the rapidly increasing human population, by 2050 the demand for this cereal is expected to increase by $31 \%$ over the 683 million tons consumed in 2008 [28]. Over the course of various wheat improvement programs aimed at increasing drought tolerance and other important characteristics, the genetic basis of tolerant breeding lines and cultivated varieties has narrowed. Therefore, these new resources can provide an ideal opportunity for producing new varieties. Wild wheats are a valuable source of genes related to water deficit stress and other abiotic and biotic stresses [15,29-32]. For example, Aegilops tauschii Coss. $(2 n=2 x=14)$-the D genome progenitor of bread wheat-is a diploid and self-pollinated species that played an important role in the domestication process of wheat. This species is an important source of genetic diversity, and has a long history in wheat breeding programs [33]. Moreover, Ae. tauschii is one of the main ancestors of several Aegilops species, including Ae. cylincrica (DDCC-genome), Aegilops ventricosa (DDNN-genome), Ae. crassa (DDMM- and DDDDMM-genomes), Ae. juvenalis (DDMMNN-genome) and Ae. syriacum (DDMMSS-genome) $[34,35]$. Therefore, understanding the genetic diversity and adaptive evolution of Ae. tauschii, along with other wild wheat relatives that also possess the $\mathrm{D}$ genome, may provide significant insights for breeding superior wheat varieties.

Previously, Pour-Aboughadareh et al. [15] used CF parameters, along with several physiological and shoot biomass traits, as the selection criteria for severe drought stress, to identify genetic diversity among a core collection of wheat germplasm. Their study identified a set of wild accessions differing in Fo, Fv/Fm and Fv/Fo parameters under drought stress [15]. These parameters allowed rapid and early phenotyping of 180 accessions belonging to the 12 domesticated and wild species, in order to identify naturally-existing genetic variation and to compare the responses of different species to drought stress. According to their findings, two species (Ae. cylindrica and Ae. crassa) responded to drought better than 
the other species, including Ae. tauschii and T. aestivum. This invokes an important question: is there considerable genetic variation in CF parameters within these selected wild species that previously showed higher drought tolerance? The use of CF parameters as a suitable physiology tool can be validated by closer examination of the association between CF parameters and plant biomass under water deficit conditions.

Specifically, this can provide a reliable description of naturally occurring genetic variation for stress tolerance traits, which in turn may aid in wheat improvement for stress tolerance, for example in the context of discovering new sources of useful germplasms and alien genomes. Therefore, the current work aims to address the abovementioned question with the following objectives: (1) to evaluate the effects of water deficit stress on CF parameters and other physiological traits at the early growth stage, (2) to explore the potential relationships between CF parameters and dry biomass, and (3) to compare different $\mathrm{D}$ genome species in order to identify the more tolerant species and/or accessions.

\section{Materials and Methods}

\subsection{Plant Material, Experimental Design and Growth Conditions}

The plant material consisted of 196 Aegilops and Triticum accessions possessing the D genome, which belonged to four species: T. aestivum (AABBDD-genome), Ae. tauschii (DD-genome), Ae. cylindrica (DDCC-genome) and Ae. crassa (DDMM-genome) (Supplementary Table S1). A factorial experiment was performed in a randomized complete block design with three replications, in a research greenhouse at the Agronomy and Plant Breeding Department, Tehran University, Karaj, Iran, during the 2018-2019 growing seasons. Two levels of water stress and tested accessions were considered as the main and sub factors, respectively. Before sowing, seeds were stored at $4{ }^{\circ} \mathrm{C}$ for $72 \mathrm{~h}$ to interrupt seed dormancy. Ten seeds from each accession were sown in plastic pots $(20 \mathrm{~cm}$ diameter, $40 \mathrm{~cm}$ height), filled with equal parts sand, soil and humus. The pots were well-irrigated to ensure seed germination. The seedlings were grown under long daylight conditions (16 h photoperiod), with an air temperature of $25 \pm 2{ }^{\circ} \mathrm{C}$ during the day and $15 \pm 2{ }^{\circ} \mathrm{C}$ during the night. After the appearance of $2-3$ true leaves, the seedlings were thinned to five plants per pot. The water deficit treatment was initiated at the three-leaf stage of seedling growth. At this time, half of the plants were kept under well-watered (control) conditions (full field capacity $(\mathrm{FC})=95 \pm 5 \%$ ) while the other half were subjected to $30 \pm 5 \%$ FC (water stress) for 20 days. The FC was determined according to the method described by Souza et al. [36]. Thirty days after sowing, CF parameters were recorded, along with other physiological traits and shoot biomass.

\subsection{Chlorophyll Fluorescence (CF) Parameters}

CF parameters were measured using a portable Optic-Science OS-30p Fluorometer (Opti-Sciences, Inc., Hudson NH, USA). Four parameters, including initial fluorescence ( $F o$ ), maximal fluorescence $(F m)$, maximum quantum yield of PSII $(\mathrm{Fv} / \mathrm{Fm})$, and maximum primary yield of PSII photochemistry $(\mathrm{Fv} / \mathrm{Fo})$, were estimated from 20 min dark-adapted leaves from control and water deficit stress conditions for each sample. For the latter two parameters, $F v$ is the maximal variable fluorescence, calculated based on $F o$ and $F m(F m-F o)$ [37].

\subsection{Chlorophyll Content and Stomatal Conductance (Gs)}

The relative chlorophyll content (SPAD index) for each accession was estimated using a portable chlorophyll meter (SPAD-502; Konic Minolta Sensing, Inc., Osaka, Japan). The measurements were taken from the adaxial surface of three leaves of differing greenness, and the values were averaged over three plants per accession. A portable Leaf Prometer device (SC-1; Decagon Devices, Inc., Pullman, WA, USA) was used to measure stomatal conductance. 


\subsection{Relative Water Content (RWC)}

Leaf samples from each seedling plant were separately harvested and washed with sterile distilled water to remove soil particles. Once the leaf fresh weight (LFW) was determined, the samples were floated on distilled water for $24 \mathrm{~h}$. Then the leaf turgid weight (LTW) of each sample was recorded. To determine the leaf dry weight (LDW), the leaf tissues were oven-dried at $70{ }^{\circ} \mathrm{C}$ for $72 \mathrm{~h}$ before weight was recorded. Finally, the RWC was estimated based on the following equation [38]:

$$
\mathrm{RWC} \%=[\mathrm{LFW}-\mathrm{LDW}] /[\mathrm{LTW}-\mathrm{LDW}] \times 100
$$

\subsection{Shoot Fresh and Dry Biomass}

The shoots of each accession were separately harvested and subjected to shoot fresh weight (SFW) calculation. After SFW determination, the samples were oven-dried at $70{ }^{\circ} \mathrm{C}$ for $72 \mathrm{~h}$, and weighed to determine the shoot dry weight (SDW).

\subsection{Statistical Analysis}

The main and interaction effects of the experimental factors were assessed with an analysis of variance (ANOVA), using the general linear model procedure in SAS software [39]. The Duncan's multiple range test (DMRT) was used to separate the test treatment means. To identify the tolerant samples, the stress tolerance index (STI) was calculated using the iPASTIC toolkit [40]. Pearson's correlation coefficient was calculated for each pair of traits, as well as STI index per growth condition using XLSTAT software (Addisonsoft XLSTAT, Paris, France). Principal component analysis (PCA) was computed for the water deficit condition and species with Kaiser's criterion (i.e., eigenvalue more than 1) using XLSTAT software. For the biplots, the accessions and the traits were represented as points and vectors, respectively, from the origin to the position of the trait.

\section{Results}

\subsection{Shoot Biomass and Leaf Water Relations}

ANOVA revealed that water deficit stress significantly affected shoot biomasses and relative water content (RWC) among accessions. The two-way interaction effect between water stress and accession was significant for shoot fresh weight (SFW) and RWC (Table 1). SFW ranged from 0.24 to $3.83 \mathrm{~g}$ plant $^{-1}$ in the control condition, and from 0.10 to $3.40 \mathrm{~g} \mathrm{plant}^{-1}$ in the water deficit condition. Shoot dry weight (SDW) varied between 0.06 and $1.18 \mathrm{~g} \mathrm{plant}^{-1}$ in the control condition, and between 0.01 and $0.59 \mathrm{~g} \mathrm{plant}^{-1}$ in the water deficit condition. RWC showed a high range of variation in both the control and water deficit conditions, ranging from 20.92 to $91.80 \%$ in the control and 20.24 to $74.75 \%$ in the water deficit condition. The overall mean across the 196 accessions decreased significantly by $33 \%$ (SFW), 62\% (SDW) and 39\% (RWC) under the stress condition as compared to the control (Table 1). The ANOVA results showed significant differences between species in the effect of water deficit stress on SFW, SDW and RWC. Moreover, within species, there were significant differences in SFW and SDW between control and water stress conditions (Figure $1 \mathrm{~A}-\mathrm{C}$ ). For example, T. aestivum and Ae. tauschii produced the highest SFW in the control condition, while T. aestivum and Ae. cylindrica produced the highest SFW in the stress condition. Under water deficit stress, the lowest reductions in SFW were observed in Ae. crassa and Ae. cylindrica (Figure 1A). In both conditions, Ae. tauschii and Ae. crassa produced the highest SDWs. The overall SDW mean of Ae. tauschii and Ae. crassa decreased by 59 and $40 \%$, respectively, under water deficit (Figure 1B). All four species showed the same capability for maintaining water content in their leaves. Two species, Ae. crassa and T. aestivum, showed the highest RWC under both conditions. These species also had the lowest reduction (32 and 36\%, respectively) due to stress, relative to the control condition (Figure 1C). 
Table 1. Analysis of variance (ANOVA) for shoot biomasses, physiological traits and chlorophyll fluorescence parameters in 196 accessions with the D genome.

\begin{tabular}{|c|c|c|c|c|c|c|c|c|c|}
\hline Source of variation & df & SPAD & Gs & Fo & $F v / F m$ & $F v / F o$ & RWC & SFW & SDW \\
\hline Water treatment $(\mathrm{W})$ & 1 & $8050.75^{* * *}$ & $148635.74^{* * * *}$ & $0.024 * * *$ & $3.691 * * *$ & $285.21 * * *$ & $247912.73^{* * *}$ & $38.72 * * *$ & $45.92 * * *$ \\
\hline Accession $(\mathrm{A})$ & 195 & $53.29 * * *$ & $205.02 * * *$ & $0.001 * * *$ & $0.025 * * *$ & $2.73 * *$ & $250.69^{* * *}$ & $0.77^{* * *}$ & $0.04 * * *$ \\
\hline $\mathrm{W} \times \mathrm{S}$ & 195 & $34.35^{* * *}$ & $229.98^{* * *}$ & $0.0004 * *$ & $0.014^{* * *}$ & $3.40 *$ & $201.84^{* * *}$ & $0.19 * * *$ & $0.02 \mathrm{~ns}$ \\
\hline Error & 782 & 17.89 & 67.98 & 0.0002 & 0.003 & 2.02 & 123.46 & 0.09 & 0.02 \\
\hline \multicolumn{2}{|c|}{ Coefficient of variance (\%) } & 11.86 & 19.92 & 19.58 & 4.77 & 27.56 & 19.96 & 34.42 & 36.86 \\
\hline \multicolumn{2}{|c|}{ Max value for control condition } & 26.80 & 22 & 0.03 & 0.18 & 0.15 & 20.92 & 0.24 & 0.06 \\
\hline \multicolumn{2}{|c|}{ Min value for control condition } & 57.20 & 96.10 & 0.16 & 0.98 & 18.22 & 91.80 & 3.83 & 1.18 \\
\hline \multicolumn{2}{|c|}{ Mean for control condition } & $38.92 \pm 0.17^{\mathrm{a}}$ & $52.60 \pm 0.55^{\mathrm{a}}$ & $0.07 \pm 0.001^{b}$ & $0.82 \pm 0.003^{a}$ & $4.37 \pm 0.08^{\mathrm{a}}$ & $74.45 \pm 0.47^{a}$ & $1.09 \pm 0.02^{\mathrm{a}}$ & $0.64 \pm 0.007^{\mathrm{a}}$ \\
\hline \multicolumn{2}{|c|}{ Minimum for stress condition } & 19.20 & 14.30 & 0.03 & 0.26 & 0.20 & 20.24 & 0.10 & 0.01 \\
\hline \multicolumn{2}{|c|}{ Maximum for stress condition } & 47.60 & 55.60 & 0.17 & 0.98 & 13.34 & 74.75 & 3.40 & 0.59 \\
\hline \multicolumn{2}{|c|}{ Mean for stress condition } & $33.67 \pm 0.24^{b}$ & $30.12 \pm 0.31^{b}$ & $0.08 \pm 0.001^{\mathrm{a}}$ & $0.70 \pm 0.004^{b}$ & $3.38 \pm 0.04^{b}$ & $45.41 \pm 0.55^{b}$ & $0.72 \pm 0.01^{\mathrm{b}}$ & $0.24 \pm 0.005^{b}$ \\
\hline \multicolumn{2}{|c|}{$\begin{array}{l}\text { Percentage change due to stress relative } \\
\text { to control condition }{ }^{+}\end{array}$} & 13 & 43 & -13 & 14 & 23 & 39 & 33 & 62 \\
\hline
\end{tabular}

SPAD the relative chlorophyll content, Gs stomatal conductance, Fo initial fluorescence, $F v / F o$ the maximum primary yield of photochemistry, $F v / F m$ the maximum quantum efficiency, SFW shoot fresh weight $\left(\mathrm{g} \mathrm{plant}^{-1}\right), S D W$ shoot dry weight $\left(\mathrm{g} \mathrm{plant}^{-1}\right)$. $\mathrm{ns}^{*}{ }^{*},{ }^{* *}$ and ${ }^{* * *}$ : non-significant and significant at the $0.05,0.01$ and 0.001 probability levels, respectively. ${ }^{\dagger}$ Negative number indicates value higher than the control condition. Means with various letters ( $a$ and $b$ ) in each column are significantly different according to the Duncan's multiple range test (DMRT) at 0.01 probability level. 

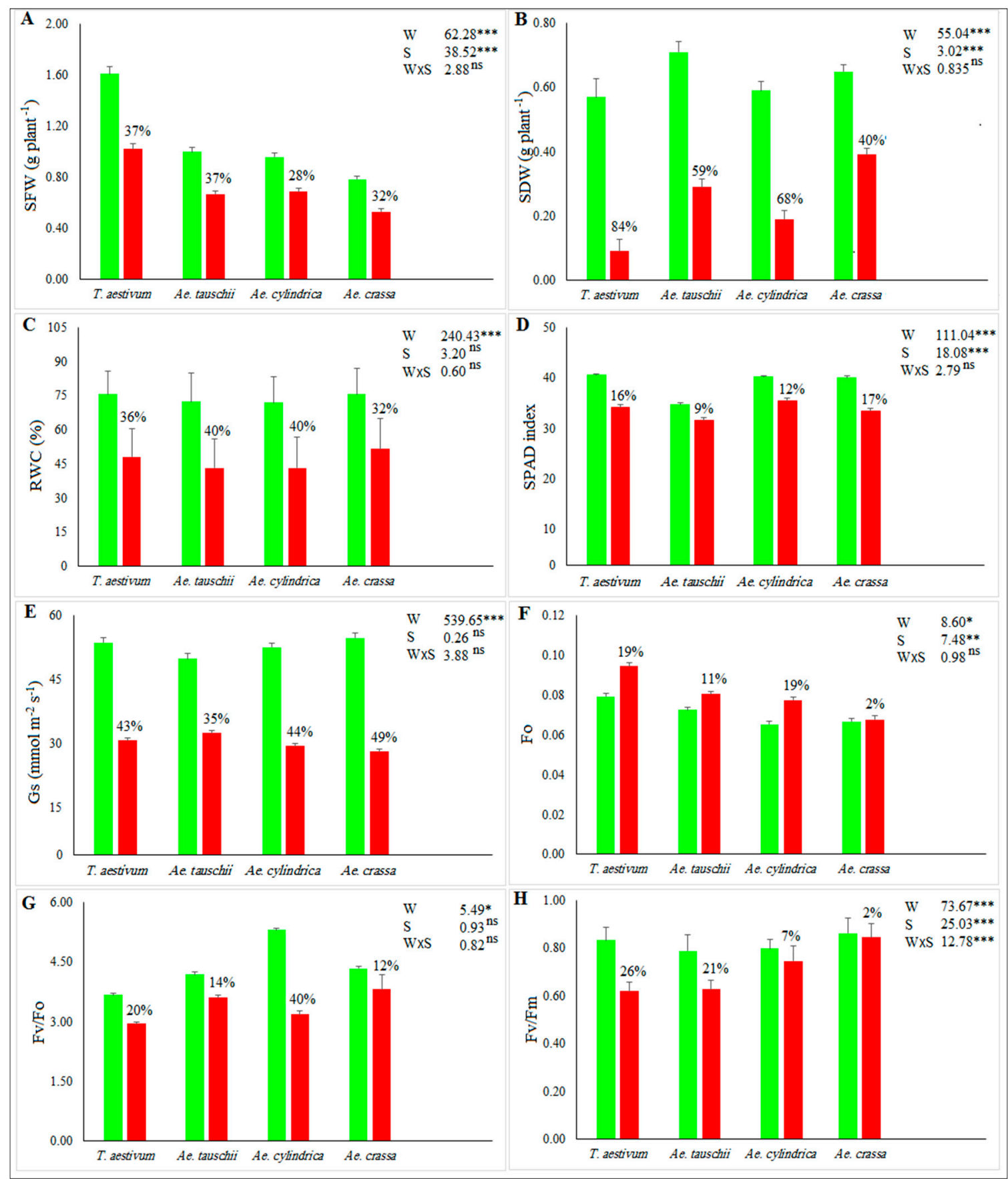

Figure 1. Effect of water deficit stress on measured traits: (A) shoot fresh weight (SFW) per plant; (B) shoot dry weight (SDW) per plant; (C) relative water content (RWC); (D) relative chlorophyll content (SPAD); (E) stomatal conductance (Gs); (F) initial fluorescence (Fo); (G) maximum primary yield of photochemistry $(\mathrm{Fv} / \mathrm{Fo}) ;(\mathbf{H})$ maximum quantum efficiency $(\mathrm{Fv} / \mathrm{Fm})$ of four species possessing the D genome. Decline (\%) due to water deficit stress compared to the control condition is indicated by red bars. Vertical lines on each bar indicate SE. W and S indicate water deficit stress treatment and species, respectively. Ns, ${ }^{*},{ }^{* *}$ and ${ }^{* * *}$ indicate non-significant and significant at the $0.05,0.01$ and 0.001 probability levels, respectively. $\mathrm{W}, \mathrm{S}, \mathrm{W} \times \mathrm{S}$ indicate water deficit stress, species and their interaction effects, respectively.

\subsection{Relative Chlorophyll Content and Stomatal Conductance}

Relative chlorophyll content (SPAD reading) and stomatal conductance (Gs) were significantly affected by water deficit stress; significant differences in these parameters were observed among 
accessions. Moreover, the two-way interaction effect was significant for both SPAD and Gs parameters. Water deficit stress caused a $13 \%$ decline in chlorophyll content compared to the control (range: $26.80-57.20 \%$ in the control, $19.20-47.60 \%$ in the stress condition). Water stress also caused a $43 \%$ decrease in Gs compared to the control condition (range: $22-96.10 \mathrm{mmol} \mathrm{m}^{-2} \mathrm{~s}^{-1}$ in the control, $14.30-55.60 \mathrm{mmol} \mathrm{m}^{-2} \mathrm{~s}^{-1}$ in the stress condition) (Table 1). The species responded differently to water stress in terms of the SPAD index: the lowest reduction occurred in Ae. tauschii and Ae. cylindrica under the stress condition (Figure 1D). However, there was no significant difference among species for the Gs parameter. The lowest reduction due to stress occurred in Ae. cylindrica $(40 \%)$ and Ae. crassa $(49 \%)$ (Figure 1E).

\subsection{Chlorophyll Fluorescence Parameters}

Water deficit stress had a significant effect on initial fluorescence $(F o)$, maximum primary yield of photochemistry $(F v / F o)$, and quantum efficiency $(F v / F m)$. The accessions generally responded differently under water stress, as the interaction between them and water stress was significant for all CF parameters (Table 1). On average, the Fo parameter in all 196 accessions increased significantly by $13 \%$ under stress as compared to the control. Values for this parameter ranged from 0.03 to 0.16 in the control, and from 0.03 to 0.17 in the stress condition. Water stress decreased the $F v / F o$ parameter by $23 \%$, with an overall mean of 4.37 in the control and 3.38 in the stress condition. The average of the Fv/Fm parameter among the 196 accessions was 0.82 and 0.70 in the control and stress conditions, respectively (i.e., in general, a significant reduction (14\%) in Fv/Fm occurred during the water deficit stress) (Table 1). ANOVA revealed that each species had a different response to water deficit stress. There was no significant effect of stress $\times$ species for the Fo parameter, but the species differed significantly for this parameter (Figure 1F). Under water deficit stress, T. aestivum and Ae. cylindrica showed the greatest increase in Fo (19\% for both species), whereas Ae. crassa showed the least increase (2\%). There was no significant effect of species or stress $\times$ species in the four species for Fv/Fo (Figure 1G). Water deficit stress caused the greatest decline in the Fv/Fo value in Ae. cylindrica (40\%) as compared with the control condition, followed by T. aestivum (20\%). The smallest reduction of this parameter was observed in Ae. crassa $(12 \%)$. There were highly significant effects of stress treatments, species and their interaction on the four species for $\mathrm{Fv} / \mathrm{Fm}$ (Figure $1 \mathrm{H}$ ). The effect of water deficit stress on this parameter was highest in T. aestivum (26\%), and lowest in Ae. crassa ( $2 \%$ decrease as compared with the control).

\subsection{Screening of Accessions Based on Stress Tolerance Index (STI)}

The STI index was estimated in order to identify the most tolerant accessions. This index ranged from 0.08 to 0.75 , with a median of 0.37. Based on the STI diagram (Figure 2), all T. aestivum accessions had values less than the median, whereas all accessions of Ae. crassa and some of Ae. tauschii and Ae. cylindrica had STIs greater than 0.37. Furthermore, five accessions of Ae. tauschii (No. 53, 56, 63, 71, and 85) and one accession of Ae. cylindrica (No. 104) showed indications of tolerance similar to the Ae. crassa accessions. As a result, the following accessions with the highest STIs (included in brackets) were identified as the most tolerant: 149 (0.69), $150(0.68), 152(0.72), 154(0.64), 155(0.70), 157(0.66)$, 160 (0.75), 163 (0.66), $164(0.64), 180(0.68), 182(0.67), 185(0.63), 186(0.65), 192(0.62)$ and $195(0.62)$. 


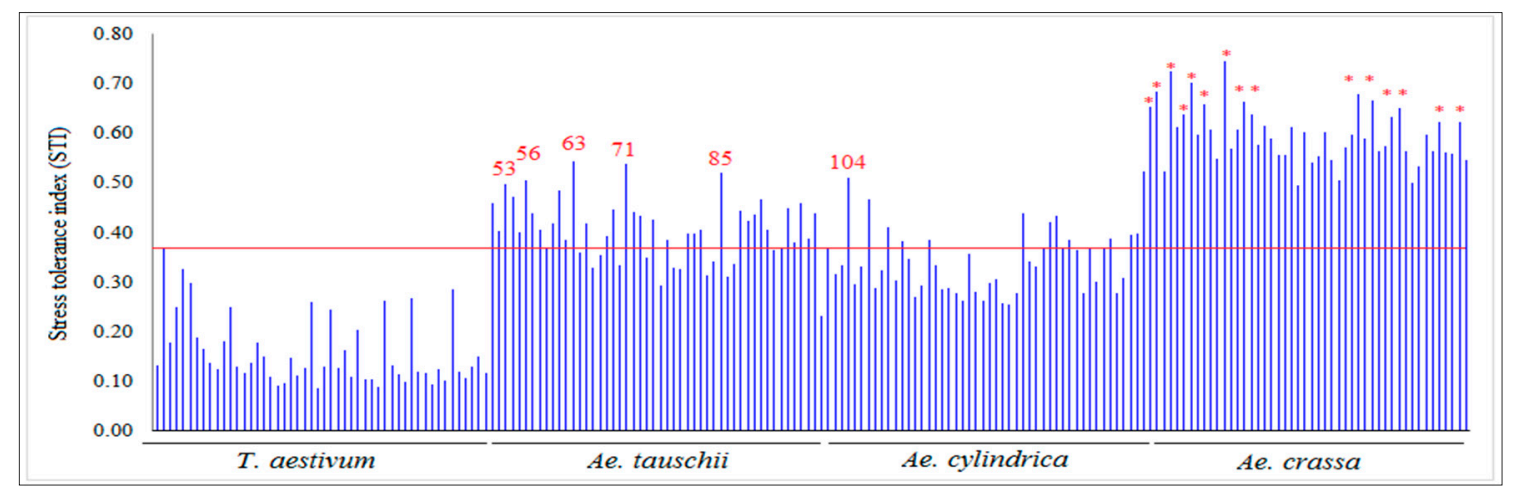

Figure 2. Stress tolerance index (STI) values for the 196 accessions possessing the D genome. Red line indicates the median value. The accession numbers 53, 56, 63, 71, 85 and 104 represent the most tolerant accessions belonging to Ae. tauschii and Ae. cylindrica species. Stars indicate the accessions with highest STI values (from the left, accession numbers 149, 150, 152, 154, 155, 157, 160, 163, 164, 180, 182, 185, 186, 192 and 195).

\subsection{Analysis of Multiple Functional Traits under Water Deficit Conditions}

Associations between the shoot biomasses, physiological traits, CF parameters, and STIs across all 196 individuals were tested with Pearson's correlation analysis (Figure 3). Under the control condition, positive and significant correlations were found between the following parameters: $F v / F m$ and SPAD; Fv/Fm and Gs; SFW and Fo; SFW and RWC; RWC and Fv/Fm; STI and SDW. Under water deficit stress, positive and significant correlations were found between the following parameters: SPAD and Gs; SPAD and SFW; Fo and SFW; Fv/Fm and $\mathrm{Fv} / F o ; F v / F m$ and SDW; Fv/Fm and RWC; Fv/Fm and STI; Fv/Fo and SDW; Fv/Fo and RWC; Fv/Fo and STI. A strong and negative correlation was found between $F o$ and SDW under both conditions. This result showed that CF parameters were affected by water deficit, and the species were consistent in their responses to this stress.

A principal component analysis based on STI and different traits and parameters was used to further test if the traits were associated when the plants experienced water deficit condition. The first two principal components (PCs) combined accounted for $53.36 \%$ of the total variation in the water deficit condition. PC1 explained $39.13 \%$ of the total variation, and was positively associated with $\mathrm{Fv} / \mathrm{Fm}, \mathrm{Fv} / \mathrm{Fo}$, SDW, RWC and STI; hence, it was named the photochemistry capacity and dry matter potential. PC2 explained $14.23 \%$ of the total variation, and was strongly influenced by SFW, RWC and SPAD; hence, it was named the leaf greenness component (Table S2). The PCA-based biplot was used to explore associations between traits (Figure 4A). According to the cosine of the angle between trait vectors, positive and significant associations were found among RWC, SPAD and SFW traits. In addition, STI was significantly correlated with SDW, $F v / F m$ and $F v / F o$. Thus, these parameters can be used as a suitable physiological tool to screen for the most tolerant genotypes. The distribution pattern of the 196 accessions is shown in Figure 4B. Based on this biplot, all accessions belonging to T. aestivum were distinctly separated from Ae. crassa (except for a few samples). All accessions of Ae. tauschii and Ae. cylindrica formed a mixed group and were distributed in the center of the biplot. This biplot further indicated that Ae. crassa accessions had a strong relationship with PSII photochemistry capacity and water deficit stress tolerance. 


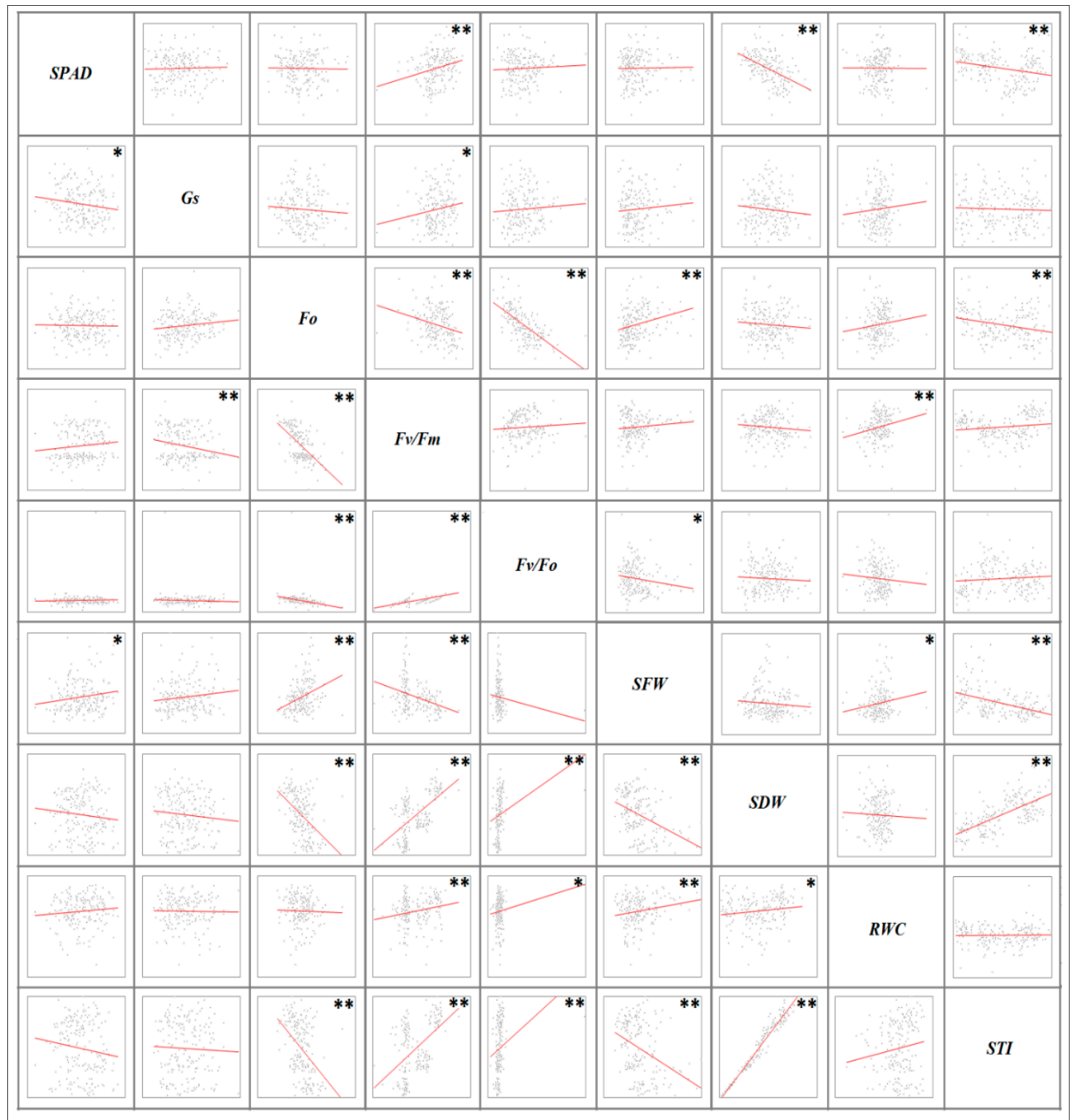

Figure 3. Pearson's correlation coefficients among the different measured traits under control (above the diagonal) and water deficit stress conditions (below the diagonal). SPAD, Gs, Fo, Fv/Fo, Fv/Fm, SFW, SDW and STI indicate the relative chlorophyll content, stomatal conductance, initial fluorescence, maximum primary yield of photochemistry, maximum quantum efficiency, shoot fresh weight, shoot dry weight and stress tolerance index, respectively. * and ${ }^{* *}$ show significance at the 0.05 and 0.01 probability levels, respectively; SFW, shoot fresh weight; SDW, shoot dry weight; RWC, relative water content; STI, stress tolerance index.

To better dissect the relationships among traits and explore how they were associated within each species, PCA analysis was computed separately for each species. For T. aestivum, Ae. tauschii, Ae. cylindrica and Ae. crassa accessions, the first two PCs accounted for 56.96, 54.17, 53.52 and $65.65 \%$ of the total variation under water deficit condition, respectively (Figure 5). In each of their biplots, STI had a positive and strong correlation with SFW and SDW; Fv/Fm was significantly correlated with Fv/Fo. Positive and significant correlations were found between RWC and SPAD in three species (T. aestivum, Ae. tauschii and Ae. cylindrica) (Figure 5A-D). Associations among RWC, SPAD, Fv/Fm and $\mathrm{Fv} / \mathrm{Fo}$ were found to be positive, and the biplots rendered for T. aestivum and Ae. crassa showed the same pattern for these relationships (Figure 5A,C). 


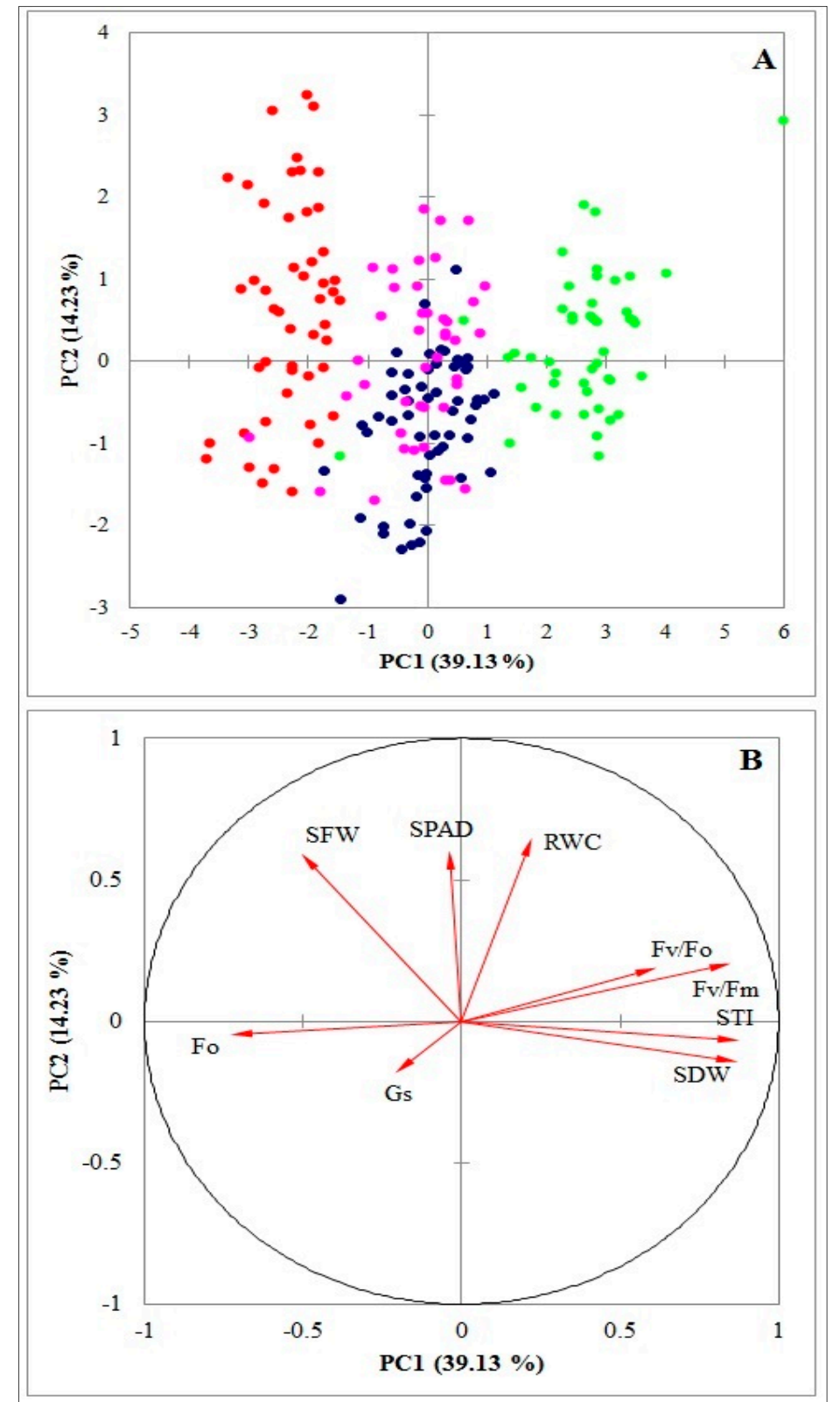

Figure 4. (A) Distribution of the 196 accessions possessing the D genome, based on the two first components under water deficit stress. Red, blue, green and pink circles indicate T. aestivum, Ae. tauschii, Ae. crassa and Ae. cylindrica accessions, respectively. (B) PCA-based biplot illustrating the relationships between the measured traits and STI. SPAD, Gs, Fo, Fv/Fo, Fv/Fm, SFW, SDW and STI indicate the relative chlorophyll content, stomatal conductance, initial fluorescence, maximum primary yield of photochemistry, maximum quantum efficiency, shoot fresh weight, shoot dry weight and stress tolerance index, respectively; PC, principal component.

\subsection{Analysis of Multiple Functional Traits under Water Deficit Conditions}

It was difficult to identify the best accessions based on a single trait under water stress condition. Therefore, we used the average of sum of ranks (ASR) of all traits to select the most tolerant accessions (i.e., those with low ASR values). Based on this method, we identified 20 accessions with low ASR values (Table 2). Of these, one accession (No. 85) belonged to Ae. tauschii, and the rest belonged to $A$. crassa. The ANOVA showed a high level of variability for $F o, F v / F m, F v / F o$ and SDW among this subset of "superior" selected accessions. Values for SPAD, Gs, SFW, SDW and RWC differed significantly between the two water treatments. The interaction effect between these selected accessions 
and water treatments was significant for all measured traits except Fo, SFW and RWC (Table 2). The average values of SPAD, Fv/Fm, Fv/Fo and SDW across the 20 accessions selected were higher than the overall means under water deficit stress, suggesting that these selected accessions have potential in breeding for drought tolerance in the aforementioned traits. The five accessions (No. 154, 155, 180, 192 and 195) with the lowest ASR values were identified as the best material.
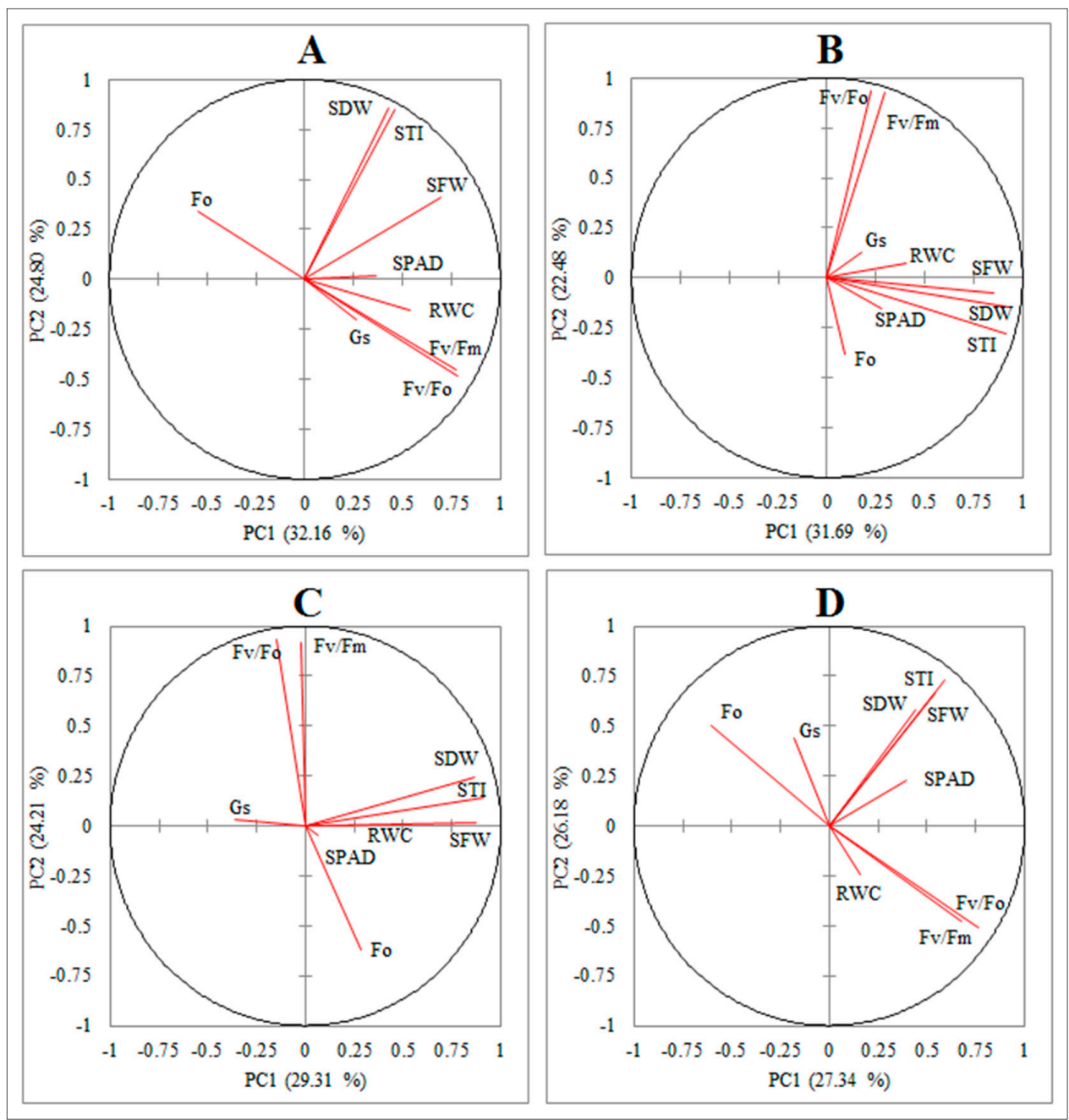

Figure 5. Biplots based on the different physio-chemical traits, shoot biomasses and STI index in: (A) T. aestivum, (B) Ae. tauschii, (C) Ae. cylindrica and (D) Ae. crassa species. SPAD, Gs, Fo, Fv/Fo, Fv/Fm, SFW, SDW and STI indicate the relative chlorophyll content, stomatal conductance, initial fluorescence, maximum primary yield of photochemistry, maximum quantum efficiency, shoot fresh weight, shoot dry weight and stress tolerance index, respectively.

PCA revealed that PC1 and PC2 explained $52.13 \%$ of the total physic-chemical variation among the 20 selected accessions. PC1 strongly associated with SPAD, Fv/Fm, Fv/Fo, SDW, RWC and STI, whereas PC2 positively associated SFW, SDW, STI and SPAD (eigenvalues and factor loadings not shown). Hence, high PCs values are indicative of potential drought-tolerant accessions. Accordingly, three accessions (No. 160, 180 and 150) were selected for shoot biomasses with high STI values. Moderate values of PC1 and PC2 confirmed the earlier selection based on ASR values; the five selected accessions listed above were in the center of the biplot, and showed positive associations with all traits (Figure 6). 
Table 2. Mean values of physio-chemical traits and shoot biomasses in the selected accessions for water deficit stress condition.

\begin{tabular}{|c|c|c|c|c|c|c|c|c|c|c|c|c|c|c|c|c|c|}
\hline \multirow{2}{*}{ Code } & \multicolumn{2}{|c|}{ SPAD } & \multicolumn{2}{|c|}{ Gs } & \multicolumn{2}{|c|}{ Fo } & \multicolumn{2}{|c|}{$F v / F m$} & \multicolumn{2}{|c|}{$F v / F o$} & \multicolumn{2}{|c|}{ SFW } & \multicolumn{2}{|c|}{ SDW } & \multicolumn{2}{|c|}{ RWC } & \multirow{2}{*}{ ASR } \\
\hline & Con. & Str. & Con. & Str. & Con. & Str. & Con. & Str. & Con. & Str. & Con. & Str. & Con. & Str. & Con. & Str. & \\
\hline 85 & 33.57 & 32.10 & 35.50 & 40.63 & 0.06 & 0.070 & 0.82 & 0.65 & 4.29 & 4.10 & 1.07 & 1.08 & 0.85 & 0.31 & 66.53 & 45.78 & 60 \\
\hline 149 & 47.13 & 30.53 & 49.30 & 28.60 & 0.05 & 0.050 & 0.86 & 0.86 & 4.32 & 3.75 & 0.82 & 0.75 & 0.71 & 0.40 & 74.77 & 49.37 & 57 \\
\hline 150 & 43.20 & 34.17 & 37.47 & 24.83 & 0.06 & 0.073 & 0.86 & 0.83 & 3.68 & 3.24 & 0.86 & 0.73 & 0.65 & 0.45 & 82.11 & 53.21 & 61 \\
\hline 151 & 42.00 & 26.93 & 47.87 & 38.83 & 0.06 & 0.067 & 0.87 & 0.87 & 3.79 & 3.96 & 0.79 & 0.40 & 0.60 & 0.38 & 80.27 & 58.14 & 62 \\
\hline 154 & 41.47 & 34.87 & 62.53 & 32.60 & 0.06 & 0.060 & 0.88 & 0.89 & 4.79 & 4.58 & 0.60 & 0.53 & 0.66 & 0.42 & 69.59 & 54.54 & 41 \\
\hline 155 & 37.87 & 36.97 & 72.10 & 34.90 & 0.07 & 0.063 & 0.90 & 0.88 & 5.15 & 4.40 & 0.95 & 0.82 & 0.76 & 0.40 & 77.07 & 52.68 & 30 \\
\hline 157 & 40.00 & 37.67 & 50.17 & 36.27 & 0.10 & 0.100 & 0.84 & 0.85 & 4.04 & 4.78 & 0.84 & 0.61 & 0.65 & 0.44 & 76.45 & 55.31 & 49 \\
\hline 158 & 42.00 & 32.43 & 55.90 & 30.00 & 0.06 & 0.057 & 0.91 & 0.85 & 6.50 & 3.53 & 0.93 & 0.65 & 0.69 & 0.38 & 73.30 & 56.85 & 59 \\
\hline 160 & 41.70 & 34.13 & 52.93 & 26.60 & 0.06 & 0.053 & 0.87 & 0.85 & 4.04 & 3.72 & 1.21 & 0.85 & 0.63 & 0.51 & 75.39 & 56.92 & 45 \\
\hline 161 & 43.57 & 32.50 & 48.33 & 30.87 & 0.04 & 0.077 & 0.82 & 0.87 & 3.31 & 4.03 & 0.64 & 0.52 & 0.64 & 0.38 & 71.06 & 47.27 & 61 \\
\hline 163 & 39.17 & 29.57 & 50.17 & 39.13 & 0.06 & 0.063 & 0.88 & 0.89 & 5.13 & 4.42 & 0.84 & 0.47 & 0.73 & 0.39 & 77.28 & 50.06 & 55 \\
\hline 172 & 40.97 & 37.43 & 53.53 & 23.10 & 0.06 & 0.057 & 0.87 & 0.97 & 5.61 & 10.57 & 0.66 & 0.46 & 0.67 & 0.39 & 77.88 & 61.96 & 52 \\
\hline 180 & 38.80 & 37.47 & 55.43 & 29.17 & 0.05 & 0.067 & 0.88 & 0.85 & 3.88 & 3.61 & 0.91 & 0.69 & 0.64 & 0.46 & 75.28 & 53.81 & 43 \\
\hline 181 & 40.37 & 33.60 & 49.23 & 26.57 & 0.06 & 0.057 & 0.90 & 0.85 & 4.71 & 3.56 & 1.03 & 0.58 & 0.63 & 0.41 & 78.07 & 55.25 & 61 \\
\hline 184 & 43.83 & 36.60 & 63.27 & 24.20 & 0.08 & 0.087 & 0.86 & 0.88 & 4.03 & 4.29 & 0.91 & 0.44 & 0.61 & 0.41 & 84.14 & 52.69 & 66 \\
\hline 185 & 40.17 & 40.73 & 59.67 & 24.60 & 0.06 & 0.070 & 0.87 & 0.84 & 3.61 & 3.32 & 0.81 & 0.73 & 0.69 & 0.39 & 72.20 & 57.93 & 48 \\
\hline 186 & 41.40 & 34.30 & 57.50 & 23.83 & 0.05 & 0.060 & 0.86 & 0.87 & 4.52 & 3.93 & 0.59 & 0.37 & 0.76 & 0.37 & 78.82 & 55.52 & 64 \\
\hline 192 & 40.87 & 37.83 & 54.30 & 23.37 & 0.07 & 0.073 & 0.86 & 0.88 & 3.97 & 4.28 & 1.13 & 0.83 & 0.66 & 0.41 & 79.28 & 56.40 & 43 \\
\hline 193 & 36.07 & 39.90 & 68.83 & 21.20 & 0.06 & 0.067 & 0.87 & 0.87 & 3.56 & 3.99 & 0.78 & 0.51 & 0.65 & 0.37 & 77.04 & 48.08 & 63 \\
\hline 195 & 40.00 & 38.33 & 81.40 & 34.47 & 0.06 & 0.067 & 0.88 & 0.88 & 4.16 & 4.38 & 0.61 & 0.32 & 0.64 & 0.42 & 71.60 & 53.24 & 41 \\
\hline W & \multicolumn{2}{|c|}{$* * *$} & \multicolumn{2}{|c|}{$* * *$} & \multicolumn{2}{|c|}{ ns } & \multicolumn{2}{|c|}{ ns } & \multicolumn{2}{|c|}{ ns } & \multicolumn{2}{|c|}{$* * *$} & \multicolumn{2}{|c|}{$* * *$} & \multicolumn{2}{|c|}{$* * *$} & \\
\hline A & \multirow{2}{*}{\multicolumn{2}{|c|}{ ns }} & \multirow{2}{*}{\multicolumn{2}{|c|}{$\begin{array}{l}* * \\
* * *\end{array}$}} & \multirow{2}{*}{\multicolumn{2}{|c|}{$\begin{array}{l}* * \\
\mathrm{~ns}\end{array}$}} & & & & & & & & & & & \\
\hline $\mathrm{W} \times \mathrm{A}$ & & & & & & & \multicolumn{2}{|c|}{$* *$} & \multicolumn{2}{|c|}{ * } & \multicolumn{2}{|c|}{ ns } & \multicolumn{2}{|c|}{$* * *$} & \multicolumn{2}{|c|}{ ns } & \\
\hline MS & 40.71 & 34.90 & 55.27 & 29.69 & 0.06 & 0.07 & 0.87 & 0.86 & 4.36 & 4.32 & 0.85 & 0.62 & 0.68 & 0.40 & 75.91 & 53.75 & \\
\hline MT & 38.92 & 33.68 & 52.60 & 30.12 & 0.07 & 0.08 & 0.82 & 0.71 & 4.37 & 3.48 & 1.09 & 0.73 & 0.56 & 0.24 & 72.23 & 65.62 & \\
\hline${ }^{+} \mathrm{D}$ & 1.79 & 1.23 & 2.67 & -0.43 & -0.01 & -0.01 & 0.05 & 0.15 & -0.01 & 0.84 & -0.24 & -0.11 & 0.11 & 0.16 & 3.67 & -11.87 & \\
\hline
\end{tabular}

SPAD the relative chlorophyll content, Gs stomatal conductance, Fo initial fluorescence, Fv/Fo the maximum primary yield of photochemistry, $F v / F m$ the maximum quantum efficiency, $S F W$ shoot fresh weight $\left(\mathrm{g} \mathrm{plant}^{-1}\right)$, SDW shoot dry weight $\left(\mathrm{g} \mathrm{plant}^{-1}\right)$, Con control conditions, Str water deficit stress conditions, ASR average of sum of ranks. $\mathrm{ns}^{*}, * *$ and ${ }^{* * *}$ : non-significant and significant at the $0.05,0.01$ and 0.001 probability levels, respectively. $W$ water deficit stress condition, $A$ accession, $M S$ mean values in selected accessions, $M T$ mean values in total accessions, $D$ standard division. ${ }^{\dagger}$ Negative number indicates value higher than the control condition.

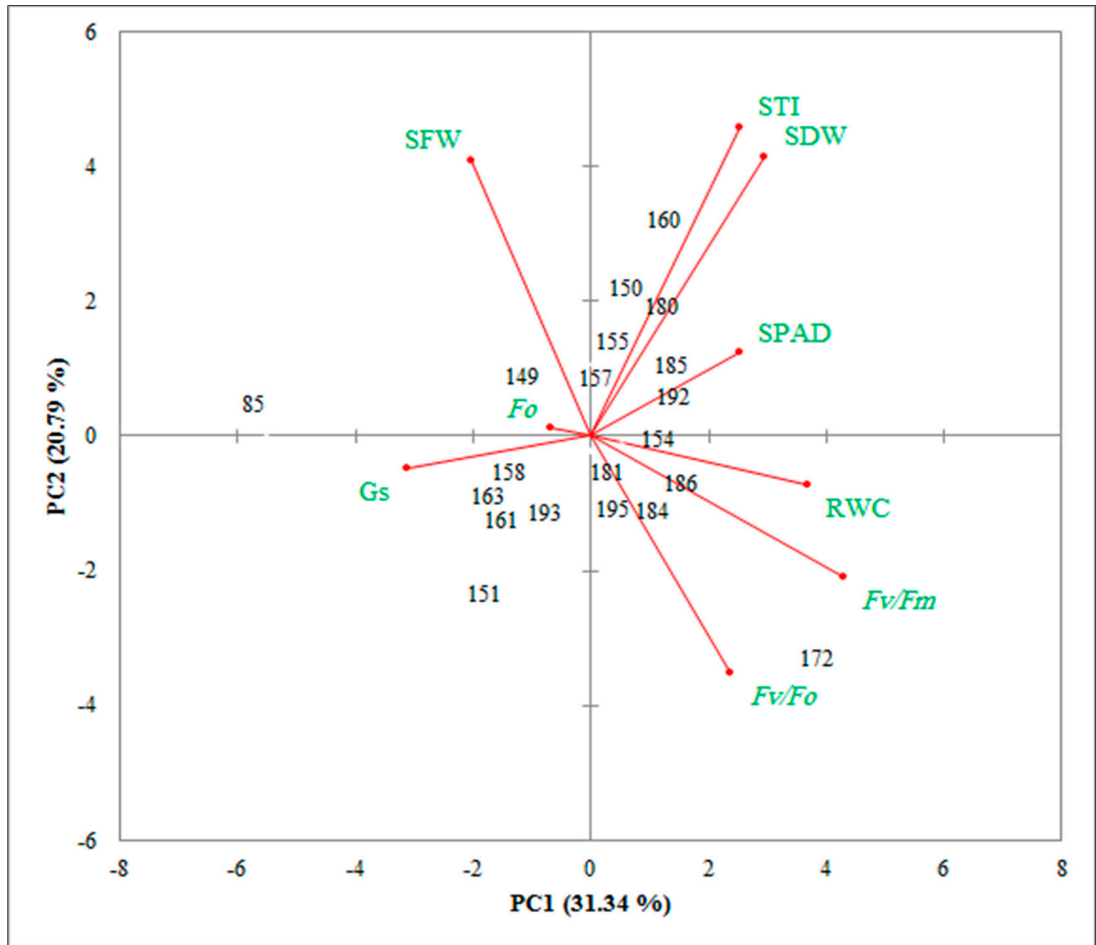

Figure 6. Biplot of the different physio-chemical traits, shoot biomass-related traits, and STI of Ae. crassa accessions under the water deficit stress condition. SPAD, Gs, Fo, Fv/Fo, Fv/Fm, SFW, SDW and STI indicate the relative chlorophyll content, stomatal conductance, initial fluorescence, maximum primary yield of photochemistry, maximum quantum efficiency, shoot fresh weight, shoot dry weight and stress tolerance index, respectively. 


\section{Discussion}

Among the various abiotic stresses, water deficit is the major detrimental factor for growth and productivity of many crops. The development of cultivars that are tolerant to water deficit or drought is one promising strategy for improving wheat yield under stressful environments [28]. Screening for resistance to water deficit in large quantities of plant materials should be inexpensive, fast, easy and non-destructive, especially if it allows taking several measurements on the same plants $[15,41]$. Importantly, greenhouse methods that test early growth stages under optimal growth conditions need to be significantly associated with the water deficit tolerance observed in adult plants under stressful environmental conditions [42]. In this regard, Kumar et al. [43] state that variation in physiological and biochemical characteristics of seedling plants are all important in determining the scale of water deficit resistance between and within plant species. Thus the early growth stage may be suitable for revealing the physiological and biochemical responses of different wheat cultivars [44]. Indeed, this approach has been successfully used to develop and introduce drought-tolerant genotypes in maize, cotton and wheat [45-47].

The genus Aegilops is known to be an ideal genetic source for wheat breeding programs, due to its high diversity of species and genomes. Among the Aegilops species, Ae. tauschii (a D genome donor) and Ae. speltoides (a putative B genome donor) directly contributed two of the three bread wheat genomes. Hence, these wild relatives are significant for improving the genetic potential of modern wheat varieties to withstand different environmental stresses. Over the last decades, numerous studies have explored the responses of wild relatives of wheat, especially Ae. tauschii, to various abiotic stresses. Their results have revealed a high level of genetic diversity among this germplasm. Therefore, discovering the adaptive potential of these species under stressful environments can provide new insights towards understanding the genetic basis of drought resistance, and aid in developing new wheat varieties with enhanced resistance characteristics. To the best of our knowledge, this is the first study to explore water deficit stress tolerance in Ae. tauschii and other species with a D genome by imposing water stress at the early stage of growth. The present study uncovered a high level of variability among species and accessions, in terms of physiological characteristics, shoot biomasses and photosynthetic parameters. The species tested in this work were previously selected for their water deficit response, based on our greenhouse evaluation of their physiological, biochemical, and photosynthetic parameters, as well as their root system architecture features [7,15,32].

In this study, we measured chlorophyll fluorescence and physiological responses to water deficit stress in seedlings of three Aegilops species, and one bread wheat species collected from different areas. The response to water deficit differed among the 196 accessions tested. Under water deficit stress, all of the measured parameters except Fo decreased by varying degrees. Specifically, shoot dry biomasses, stomatal conductance and RWC fell the most under water deficit conditions (Table 1). Shoot fresh and dry biomasses are among the most important traits to screen for when identifying tolerant genotypes at the seedling stage. In this study, shoot fresh and dry biomasses were severely reduced in each of the species, although the level of reduction under water stress varied between species (Figure 1A,B). A previous study found a similar change in SFW and SDW patterns in these species, with Ae. crassa being less affected by stress than other Aegilops species or bread wheat accessions [15]. Leaf RWC is another key physiological feature that is widely used as an indicator for defining the sensitivity of plants to tissue and cell dehydration [15]. Several studies have reported that minimal reduction in RWC during water deficit stress is indicative of stress resistance [48-51]. We observed that water deficit stress generally decreased RWC (Table 1)—significantly in Ae. cylindrica and Ae. tauschii—whereas Ae. crassa accessions showed a considerable ability to preserve water in their tissues (Figure 1C). These results are consistent with those from Wang et al. [52], who reported that water deficit also caused a decline in RWC in wheat plants. Furthermore, our results confirm those reported in a previous study that also revealed that Ae. crassa responded well to the water deficit treatment, as it can maintain a high level of water in its leaf tissues under severe water deficiency conditions [15]. 
Our results showed that water deficit stress reduced the relative chlorophyll content (SPAD reading) of all accessions (Table 1). Chlorophyll is the main component of photosynthesis-one of the physiological processes most sensitive to environmental stress [51]. Similar to high temperature, water deficiency may induce lipid peroxidase and electrolytic leakage from chloroplast and thylakoid membranes, leading to a loss of chlorophyll content [53,54]. The rate of decrease in relative chlorophyll under water deficient conditions differed across the 196 accessions (Table 1), indicating possible genetic variability for this trait. For example, Ae. tauschii showed the lowest reduction in relative chlorophyll compared to the other species. Nevertheless, the average chlorophyll content was similar across species (Figure 1D), suggesting that the similar responses of the different species may result from the presence of the D genome.

Water-related processes in plants are influenced by various factors, such as canopy temperature, leaf water potential, transpiration rate and stomatal conductance [51]. Of these, stomatal conductance (Gs) plays a crucial role in maintaining water in leaf tissue through control of transpiration. This physiological process also determines the rate of gas exchange (i.e., carbon dioxide uptake) through movement of gases between the interior and outer environments of the leaf tissue. Under water deficit stress, reduced Gs leads to reduction of reaction centers in PSII and exposure of excess energy in the chloroplasts, hence these events restrict photosynthesis [55]. In this study, water deficit stress decreased Gs by an average of $43 \%$ (Table 1); this was also found in other studies that reported a similar reduction in Gs as a result of water stress [15,56]. Interestingly, Ae. tauschii showed the lowest reduction $(35 \%)$ in Gs, although there were no significant differences among the four tested species. Similarly, Molnar et al. [57], Dulai et al. [58] and Chunyan et al. [59] also found considerable stomatal conductance in Ae. tauschii compared with other Aegilops species and bread wheat genotypes when exposed to water deficit conditions. Hence it seems that this wild progenitor has the potential to improve the drought tolerance of bread wheat through intergenetic crossing [57].

Among the wild relatives of wheat with a D genome, we noted high variability in shoot dry matter and other important measured physiological traits, such as RWC, relative chlorophyll content and stomatal conductance. Variation in these traits suggests that the capability and sustainability of hybridization might also vary. Additionally, since this variation was observed in response to severe water deficit stress, it could be suggested that this variability is genetically determined. Hence, two species (Ae. tauschii and Ae. crassa) could be valuable for drought tolerance breeding. The hybridization of these wild wheats could also lead to the introgression of favorable genes into novel wheat populations, and provide a source of new genetic variation via recombination $[15,60]$.

Plant growth and development depends on the complex of photosynthetic and biochemical activities, which is often affected by various environmental factors. During the process of photosynthesis, radiation is captured by chlorophyll and additional photosynthetic pigments, and finally transferred to the photosystem centers (PSI and PSII) where transformation of the quantum photosynthetic procedure takes place [9]. Chlorophyll fluorescence (CF) measurement is a non-invasive approach that is widely used in plant stress physiology studies, as it allows investigation of the various functional levels of the photosynthesis mechanisms $[1,15,61,62]$. Among the CF parameters, Fo, $\mathrm{Fv} / \mathrm{Fm}$ and $\mathrm{Fv} / \mathrm{Fo}$ values are very important indicators of plant health and photosynthetic activity under adverse environmental conditions. Initial fluorescence $(F o)$ is the primary fluorescence level when all light-harvesting complexes (antenna pigment) associated with the PSII are assumed to be dark-adapted [63]. Disruption in energy transfer to PSII, and any difficulty/degradation of PSII, are the most likely causes of an increase in Fo levels when exposed to stressful environments [64]. Hence, this parameter can be used to indicate the stability of the antenna complex [9]. In the present study, Fo increased significantly with water deficit stress compared to the control condition (Table 1). Similarly, previous studies have also reported a trend of increasing values of Fo under water deficit stress in different crops $[1,14,15,62,64,65]$. The specific trend in $F o$ in response to water deficit stress observed in our study was as follows: Ae. cylindrica $(19 \%)>$ T. aestivum $(19 \%)>$ Ae. tauschii $(11 \%)>$ Ae. crassa $(2 \%)$ (Figure 1F). In other words, there was less of an increase in the species with the MD and D 
genomes compared to the species with $\mathrm{ABD}$ and DC genomes. This might suggest that Ae. tauschii and Ae. crassa present more stability in their thylakoid membrane under water deficit stress. Similar to our result, Pour-Aboughadareh et al. [15] recommended using Fo to identify drought-tolerant wild relatives. They also noted that the photosynthetic apparatus appeared to be most stable in Ae. crassa.

The maximum quantum yield of PSII ( $F v / F m$ parameter) is the ratio of variable fluorescence $(F v)$ to maximal fluorescence $(F m)$. The increase in $F m$ level occurs when a high intensity flash has been applied, and all of the light-harvesting complexes are assumed to be closed. In this situation, a state of electrical transfer is reflected when active radiation is passed to PSII. The Fv was calculated as $F m-F o$, and represents the maximum quantum yield of CF [66]. The Fv/Fm parameter can be applied to estimate the potential efficiency of PSII by taking dark-adapted measurements [61,63]. Furthermore, the maximum primary yield of PSII photochemistry $(\mathrm{Fv} / \mathrm{Fo})$ is another important photochemical parameter that provides an estimation of leaf photosynthetic capacity. Like the other measured traits, $\mathrm{Fv} / \mathrm{Fm}$ and $\mathrm{Fv} / \mathrm{Fo}$ were affected by water deficit stress (14\% and $23 \%$ reduction compared to the control condition, respectively) (Table 1). According to Ahmad et al. [67], a reduction in these traits caused by water deficit stress suggests a possible inhibition of photochemistry centers, which may be due to deficient energy displacement from the antenna chlorophyll complex to the PSII. As shown in Figure 1G, there is no significant difference among species. However, Ae. crassa and Ae. tauschii showed the lowest reduction in Fv/Fo compared to the bread wheat and Ae. cylindrica accessions. There was a high level of variability among the four tested species in Fv/Fm (Figure 1H). The lowest reduction of this parameter was observed in Ae. crassa and Ae. cylindrica. The smaller reduction in Fv/Fo and Fv/Fm in Ae. crassa reveals that the PSII of this species withstands water deficit stress better than those of the other species and reflects the fact that a higher defensive ability of PSII is a significant tolerance mechanism for this wild wheat. This result is in accordance with previous experiments on water deficit stress-treated Triticum and Aegilops accessions [14,15,58]. In general, this result reveals that $\mathrm{Fv} / \mathrm{Fo}$ and $\mathrm{Fv} / \mathrm{Fm}$ are key indices that can also be used for screening large collection material for water deficit-stress tolerance under controlled growth conditions. Moreover, our findings indicated that the photosynthetic system could be damaged more in the domesticated wheat genotypes, and even Ae. tauschii and Ae. cylindrica accessions. However, Ae. Crassa-a wild form with an alien genome (MD) - may be better adapted to avoiding harmful effects from water deficit stress. Thus genetic diversity may exist in the response to the photochemical parameters to water deficiency stress. Hence, wheat breeders could use this wild relative to restore lost genetic variation for drought resistance.

In this study, we used the STI as one of the yield-based drought tolerance indices to identify the most tolerant accessions. This has been recommended as the best selection index, because it identifies accessions with high biomass and stress tolerance potentials [40]. Our results showed that STI differed between 196 samples, which is in accordance with numerous reports on different crop plants that used this index to distinguish between tolerant and sensitive genotypes [68]. We revealed that this index could discriminate between samples that are better adapted to water stress, and identified the best biomass performances under water deficit stress and control conditions. This result is in accordance with those from previous studies of various plants, indicating that this index is indeed the best criterion for identifying tolerant and sensitive genotypes at the seedling and adult stages [7,15,30,69-72]. According to Figure 2, all accessions of Ae. crassa along with several accessions of Ae. cylindrica and Ae. tauschii showed considerable STI values; several Ae. crassa accessions were selected as the most tolerant accessions. This result was further supported by the results of the Pearson's correlation analysis, where STI was significantly correlated with SDW, Fv/Fo and Fv/Fm parameters (Figure 3).

The PCA biplot illustrated the associations among the measured traits, and also depicted the distribution of the all tested accessions (Figure 4). As shown in Figure 4A, all accessions of T. aestivum and Ae. crassa clearly separated in two distinct dimensions. The biplot also showed that all Ae. crassa accessions have a strong association with STI, Fv/Fm, Fv/Fo and SDW traits (Figure 4B). Hence, we suggest that this species harbors a high level of photochemical variability under water deficient conditions, and can be used in wheat breeding programs. The PCA analyses based on each species 
further confirmed that Ae. crassa and T. aestivum species showed similar relationships among the abovementioned traits (Figure 5). In order to identify the best accessions, we used a ranking method (ASR). According to this approach, 20 accessions with low values of average ranks were selected. As shown in Table 2, we found that 19 of these accessions belong to Ae. crassa; one accession belonged to Ae. tauschii. Additionally, the results of ANOVA for the selected accessions showed the high level of genetic diversity among these accessions for Gs, Fo, Fv/Fm, Fv/Fo and SFW. In fact, these results support previous findings (Figure 6) that Ae. crassa has a high level of variability and may be utilized in future breeding programs.

\section{Conclusions}

To summarize, the main findings were as follows: (i) exposure to water deficit stress at the early growth stage caused severe negative effects on growth and physiological and photochemical traits in a collection of bread wheat genotypes and its wild relatives with the D genome; (ii) the different physiological responses to water deficit stress in the tested materials occurred when water stress was applied to the seedling plants, largely supporting our first study, which indicated a high level of variability among the tested accessions; (iii) Ae. crassa accessions, especially 154, 155, 180, 192 and 195, responded well to water deficit stress and may serve as a source of ideal alleles for controlling the physiological and photosynthetic processes of water stress tolerance. Further experiments are needed to afford knowledge on the genetics of Ae. crassa's seedling drought tolerances; and (iv) Fv/Fo and $\mathrm{Fv} / \mathrm{Fm}$ had a positive and strong correlation with STI index, hence these traits could be used as the best non-invasive traits to screen for tolerant accessions.

Supplementary Materials: The following are available online at http://www.mdpi.com/2073-4395/9/9/522/s1, Table S1: Passport of the genetic materials used in this study, Table S2: The first two principal components for the 196 accessions of four Triticum and Aegilops species processing the D genome under water deficit stress condition.

Author Contributions: Conceptualization, A.P.-A., M.O. and M.R.N.; methodology, A.P.-A. and H.B.; software, A.P.-A.; validation, M.O. and A.E.; formal analysis, A.P.-A.; investigation, A.P.-A. and H.B.; resources, M.O. and A.A.M.; data curation, A.P., A.E.; writing—original draft preparation, A.P.; writing-review and editing, M.O., P.P.; visualization, A.P.-A. and M.O., A.E. and M.R.N.; supervision, M.O.; project administration, M.O.; funding acquisition, A.P.-A. and M.O.

Funding: This research received no external funding.

Acknowledgments: This research was supported by the Iran National Science Foundation (INSF) (No. 97007503). The supply of some Ae. crassa and Ae. tauschii germplasm by the National Plant Gene Bank of Iran (NPGBI) is also gratefully acknowledged.

Conflicts of Interest: The authors declare no conflict of interest.

\section{References}

1. Li, Y.; Song, H.; Xu, Z.; Zhou, G. Tracking chlorophyll fluorescence as an indicator of drought and rewatering across the entire leaf lifespan in a maize field. Agric. Water. Manag. 2019, 211, 190-201. [CrossRef]

2. Liu, B.; Martre, P.; Ewert, F.; Porter, J.R.; Challinor, A.J.; Müller, C.; Ruane, A.C.; Waha, K.; Thorburn, P.J.; Aggarwal, P.K.; et al. Global wheat production with 1.5 and $2.0^{\circ} \mathrm{C}$ above pre-industrial warming. Glob. Chang. Biol. 2019, 1428-1444. [CrossRef] [PubMed]

3. Falqueto, A.R.; Júnior, R.A.S.; Gomes, M.T.G.; Martins, J.P.R.; Silva, D.M.; Partelli, F.L. Effect of drought stress on chlorophyll a fluorescence in two rubber tree clones. Sci. Hort. 2017, 224, 238-243. [CrossRef]

4. Lawlor, D.W.; Cornic, G. Photosynthetic carbon assimilation and associated metabolism in relation to water deficits in higher plants. Plant Cell Environ. 2002, 25, 275-294. [CrossRef] [PubMed]

5. Hsiao, S.-C.; Chen, S.; Yang, I.-C.; Chen, C.-T.; Tsai, C.-Y.; Chuang, Y.-K.; Wang, F.-J.; Chen, Y.-L.; Lin, T.-S.; Lo, Y.M. Evaluation of plant seedling water stress using dynamicfluorescence index with blue LED-basedfluorescence imaging. Comput. Electron. Agric. 2010, 72, 127-133. [CrossRef]

6. Silva, P.E.M.; Cavatte, P.C.; Morais, L.E.; Medina, E.F.; Da Matta, F.M. The functional divergence of biomass partitioning, carbon gain and water use in Coffea canephora in response to the water supply: Implications for breeding aimed at improving drought tolerance. Environ. Exp. Bot. 2013, 87, 49-57. [CrossRef] 
7. Ahmadi, J.; Pour-Aboughadareh, A.; Fabtiki Ourang, S.; Mehrabi, A.A.; Siddique, K.H.M. Wild relatives of wheat: Aegilops-Triticum accessions disclose differential antioxidative and physiological responses to water stress. Acta Physiol. Plant. 2018, 40, 90. [CrossRef]

8. Ashraf, M.; Harris, P.H.C. Photosynthesis under stressful environments: An overview. Photosynthetica 2013, 51, 163-190. [CrossRef]

9. Li, R.H.; Pei-guo, G.; Baum, M.; Grando, S.; Cecccarelli, S. Evaluation of chlorophyll content and fluorescence parameters as indicators of drought tolerance in barley. Agric. Sci. China 2006, 5, 751-757. [CrossRef]

10. Guanter, L.; Zhang, Y.; Jung, M.; Joiner, J.; Voigt, M.; Berry, J.A.; Frankenberg, C.; Huete, A.R.; Zarco-Tejada, P.; Lee, J.-E.; et al. Global and time-resolved monitoring of crop photosynthesis with chlorophyll fluorescence. Proc. Natl. Acad. Sci. USA 2014, 111, 1327-1333. [CrossRef]

11. Jin, Z.; Zhuang, Q.; Wang, J.; Archontoulis, S.V.; Zobel, Z.; Kotamarthi, V.R. The combined and separate impacts of climate extremes on the current and future US rainfed maize and soybean production under elevated $\mathrm{CO}_{2}$. Glob. Chang. Biol. 2017, 23, 2687-2704. [CrossRef] [PubMed]

12. Baker, N.R. Chlorophyll fluorescence: A probe of photosynthesis in vivo. Annu. Rev. Plant Biol. 2008, 59, 89-113. [CrossRef] [PubMed]

13. Sharma, D.K.; Andersen, S.B.; Ottosen, C.O.; Rosenqvist, E. Wheat cultivars selected for high Fv/Fm under heat stress maintain high photosynthesis, total chlorophyll, stomatal conductance, transpiration and dry matter. Physiol. Plant. 2015, 153, 284-298. [CrossRef] [PubMed]

14. Hairat, S.; Khurana, P. Evaluation of Aegilops tauschii and Aegilops speltoides for acquired thermotolerance: Implications in wheat breeding programmes. Plant Physiol. Biochem 2015, 95, 65-74. [CrossRef] [PubMed]

15. Pour-Aboughadareh, A.; Ahmadi, J.; Mehrabi, A.A.; Etminan, A.; Moghaddam, M.; Siddique, K.H.M. Physiological responses to drought stress in wild relatives of wheat: Implications for wheat improvement. Acta Physiol. Plant. 2017, 39, 106. [CrossRef]

16. Zushi, K.; Matsuzoe, N. Using of chlorophyllafluorescence OJIP transients for sensing salt stress in the leaves and fruits of tomato. Sci. Hort. 2017, 219, 216-221. [CrossRef]

17. Goncalves, E.R.; Ferreira, V.M.; Silva, J.V.; Endres, L.; Barbosa, T.P.; Duarte, W.G. Gas exchange and chlorophyll a fluorescence of sugarcane varieties submitted to water stress. Rev. Bras. Eng. Agríc. Ambient. 2010, 14, 378-386.

18. Dodd, I.C. Hormonal interactionsand stomatal responses. J. Plant. Growth. Regul. 2003, 22, 32-46. [CrossRef]

19. Medici, L.O.; Azevedo, R.A.; Canellas, L.P.; Machado, A.T.; Pimentel, C. Stomatal conductance of maize under water and nitrogen deficits. Pesq. Agropec. Bras. 2007, 42, 599-601. [CrossRef]

20. Chaves, M.M.; Flexas, J.; Pinheiro, C. Photosynthesis under drought and salt stress: Regulation mechanisms from whole plant to cell. Ann. Bot. 2009, 103, 551-560. [CrossRef]

21. Flexas, J.; Bota, J.; Loreto, F.; Cornic, G.; Sharkey, T.D. Diffusive and metabolic limitations to photosynthesis under drought and salinity in C3 plants. Plant Biol. 2004, 6, 269-279. [CrossRef] [PubMed]

22. Parida, A.K.; Mittra, B.; Das, A.B.; Das, T.K.; Mohanty, P. High salinity reduces the content of a highly abundant 23-kDa protein of the mangrove Bruguiera parviflora. Planta 2005, 221, 135-140. [CrossRef] [PubMed]

23. Guo, P.; Li, R. Effects of high nocturnal temperature on photosynthetic organization in rice leaves. Acta Bot. Sin. 2000, 42, 13-18.

24. Araus, J.L.; Amaro, T.; Voltas, J.; Nakkoul, H.; Nachit, M.M. Chlorophyll fluorescence as a selection criterion for grain yield in durum wheat under Mediterranean conditions. Field. Crops Res. 1998, 55, $209-223$. [CrossRef]

25. Fracheboud, Y.; Jompuk, C.; Ribaut, J.M.; Stamp, P.; Leipner, J. Genetic analysis of cold-tolerance of photosynthesis in maize. Plant Mol. Biol. 2004, 56, 241-253. [CrossRef] [PubMed]

26. Araus, J.L.; Hogan, K.P. Leaf structure and patterns of photoinhibition in two Neotropical palms in clearings and forest understory during the dry season. Am. J. Bot. 1994, 81, 726-738. [CrossRef]

27. FAO. FAOSTAT (Food and Agriculture Organization of the United Nations: Rome, Italy). Available online: http://faostat.fao.org/site/609/DesktopDefault.aspx?PageID=609\#ancor (accessed on 28 March 2011).

28. Pradhan, G.; Prasad, V.; Fritz, A.K.; Kirkhan, M.; Gill, B. Response of Aegilops species to drought stress during reproductive stage of development. Funct. Plant Biol. 2012, 39, 51-59. [CrossRef] 
29. Zaharieva, M.; Gaulin, E.; Havaux, M.; Acevedo, E.; Monneveux, P. Drought and heat responses in the wild wheat relative Aegilops geniculate Roth: Potential interest for wheat improvement. Crop Sci. 2001, 41, 1321-1329. [CrossRef]

30. Kiani, R.; Arzani, A.; Habibi, F. Physiology of salinity tolerance in Aegilops cylindrica. Acta Physiol. Plant. 2015, 37, 135-145. [CrossRef]

31. Ahmadi, J.; Pour-Aboughadareh, A.; Fabriki Ourang, S.; Mehrabi, A.A.; Siddique, K.H.M. Screening wild progenitors of wheat for salinity stress at early stages of plant growth: Insight into potential sources of variability for salinity adaptation in wheat. Crop Pasture Sci. 2018, 69, 649-658. [CrossRef]

32. Ahmadi, J.; Pour-Aboughadareh, A.; Fabriki Ourang, S.; Mehrabi, A.A.; Siddique, K.H.M. Screening wheat germplasm for seedling root architectural traits under contrasting water regimes: Potential sources of variability for drought adaptation. Arch. Agron. Soil Sci. 2018, 64, 1351-1365. [CrossRef]

33. Luo, M.C.; Gu, Y.Q.; You, F.M.; Deal, K.R.; Ma, Y.; Hu, Y.; Huo, N.; Wang, Y.; Wang, J.; Chen, S.; et al. A 4-gigabase physical map unlocks the structure and evolution of the complex genome of Aegilops tauschii, the wheat D-genome progenitor. Proc. Natl. Acad. Sci. USA 2013, 110, 7940-7945. [CrossRef] [PubMed]

34. Lilienfeld, F.A.H. Kihara: Genome-Analysis in Triticum and Aegilops. Concluding review. Cytologia 1951, 16, 101-123. [CrossRef]

35. Kimber, G.; Sears, E.R. Assignment of genome symbols in the Triticeae. In Proceedings of the 6th International Wheat Genetics Symposium, Kyoto, Japan, November 28-December 3 1983; pp. 1195-1196.

36. Souza, C.C.; Oliveira, F.A.; Silva, I.F.; Amorim Neto, M.S. Evaluation of methods of available water determination and irrigation management in "terra roxa" under cotton crop. Rev. Bras. Eng. Agric. Amb. 2000, 4, 338-342. [CrossRef]

37. Maxwell, K.; Johnson, G.N. Chlorophyll fluorescence-A practical guide. J. Exp. Bot. 2000, 51, 659-668. [CrossRef]

38. Smart, R.E.; Bingham, G.E. Rapid estimates of relative water content. Plant Physiol. 1974, 53, $258-260$. [CrossRef] [PubMed]

39. SAS Institute. SAS/STAT User's Guide; SAS Institute Inc.: Cary, NC, USA, 2004.

40. Pour-Aboughadareh, A.; Yousefian, M.; Moradkhani, H.; Moghaddam Vahed, M.; Poczai, P.; Siddique, K.H.M. iPASTIC: An online toolkit to estimate plant abiotic stress indices. Appl. Plant Sci. 2019, 7, e11278. [CrossRef]

41. Meeks, M.; Murray, S.C.; Hague, S.; Hays, D. Measuring maize seedling drought response in search of tolerant germplasm. Agronomy 2013, 3, 135-147. [CrossRef]

42. Grzesiak, M.T.; Marcinska, I.; Jano Wiak, F.; Rzepka, A.; Hura, T. The relationship between seedling growth and grain yield under drought conditions in maize and triticale genotypes. Acta Physiol. Plant. 2012, 34, 1757-1764. [CrossRef]

43. Kumar, D. Breeding for Drought Resistance; Ashraf, M., Harris, P.J.C., Eds.; CRC Press: Boca Raton, FL, USA, 2004; pp. 145-176.

44. Dhanda, S.; Sethi, G.S.; Behl, K. Indices of drought tolerance in wheat genotypes at early stages of plant growth. J. Agron. Crop Sci. 2004, 190, 6-12. [CrossRef]

45. Tomar, S.M.S.; Kumar, G.T. Seedling survivability as a selection criterion for drought tolerance in wheat. Plant Breed. 2004, 123, 392-394. [CrossRef]

46. Longenberger, P.S.; Smith, C.W.; Thaxton, P.S.; McMichael, B.L. Development of a screening method for drought tolerance in cotton seedlings. Crop Sci. 2006, 46, 2104-2110. [CrossRef]

47. Pace, J.; Lee, N.; Naik, H.S.; Ganapathysubramanian, B.; Lubberstedt, T. Analysis of maize (Zea mays L.) seedling roots with the high-throughput image ana Rodriguez lysis tool ARIA (Automatic Root Image Analysis). PLoS ONE 2014, 9, e108255. [CrossRef] [PubMed]

48. Ozkur, O.; Ozdemir, F.; Bor, M.; Turkan, I. Physiochemical and antioxidant responses of the perennial xerophyte Capparis ovata Desf. to drought. Environ. Exp. Bot. 2009, 66, 487-492. [CrossRef]

49. Khalili, M.; Pour Aboughadareh, A.; Naghavi, M.R. Screening of drought tolerant cultivars in barley using morpho-physiological traits and integrated selection index under water deficit stress condition. Adv. Crop Sci. 2013, 3, 462-471.

50. Pour-Aboughadareh, A.; Nagavi, M.R.; Khalili, M. Water deficit stress tolerance in some of barley genotypes and landraces under field Conditions. Not. Sci. Biol. 2013, 5, 2067-3264. [CrossRef] 
51. Hussain, A.A.; Men, S.; Hussain, S.; Chen, Y.; Ali, S.; Zhang, S.; Zhang, K.; Li, Y.; Xu, Q.; Liao, C.; et al. Interactive effects of drought and heat stresses on morphophysiological attributes, yield, nutrient uptake and oxidative status in maize hybrids. Sci. Rep. 2019, 9, 3890. [CrossRef]

52. Wang, G.P.; Hui, Z.; Li, F.; Zhao, M.-R.; Zhang, J.; Wang, W. Improvement of heat and drought photosynthetic tolerance in wheat by overaccumulation of glycinebetaine. Plant Biotechnol. Rep. 2010, 4, 213-222. [CrossRef]

53. Ristic, Z.; Bukovnik, U.; Prasad, P.V.V. Correlation between heat stability of thylakoid membranes and loss of chlorophyll in winter wheat under heat stress. Crop Sci. 2007, 47, 2067-2073. [CrossRef]

54. Djanaguiraman, M.; Prasad, P.V.V.; Seppanen, M. Selenium protects sorghum leaves from oxidative damage under high temperature stress by enhancing antioxidant defense system. Plant Physiol. Biochem. 2010, 48, 999-1007. [CrossRef]

55. Pietragalla, J.; Pask, A.J.D. Physiological Breeding II; Pietragalla, H., Pask, A.J.D., Mullan, D., Reynold, M.P., Eds.; CIMMYT: Mexico, Mexico, 2012; pp. 15-17.

56. $\mathrm{Xu}, \mathrm{Z}$;; Zhou, G. Responses of leaf stomatal density to water status and its relationship with photosynthesis in a grass. J. Exp. Bot. 2008, 59, 3317-3325. [CrossRef] [PubMed]

57. Molnar, I.; Dulai, S.; Csernak, A.; Pronay, J.; Molnar-Lang, M. Photosynthetic responses to drought stress in different Aegilops species. Acta Biol. Szeged. 2005, 49, 141-142.

58. Dulai, S.; Molnar, I.; Pronay, J.; Csernak, A.; Tarnai, R.; Molnar-Lang, M. Effects of drought on photosynthetic parameters and heat stability of PSII in wheat and in Aegilops species originating from dry habitats. Acta Biol. Szeged. 2006, 50, 11-17.

59. Chunyan, W.; Maosong, L.; Jiqing, S.; Yonggang, C.; Xiufen, W.; Yongfeng, W. Differences in stomatal and photosynthetic characteristics of five diploid wheat species. Acta Ecol. Sin. 2008, 28, 3277-3283. [CrossRef]

60. Econopouly, B.; Mckay, J.; Westra, P.; Reid, S.; Helm, A.; Byrne, P. Phenotypic diversity of Aegilops cylindrica (jointed goatgrass) accessions from the western United States under irrigated and dryland conditions. Agric. Ecosyst. Environ. 2013, 164, 244-251. [CrossRef]

61. Murchie, E.H.; Lawson, T. Chlorophyll fluorescence analysis: A guide to good practice and understanding some new applications. J. Exp. Bot. 2013, 64, 3983-3998. [CrossRef] [PubMed]

62. Hazrati, S.; Tahmasbi-Sarvestani, Z.; Modarres-Sanavy, S.A.M.; Mokhtassi-Bidgoli, A.; Nicola, S. Effects of water stress and light intensity on chlorophyll fluorescence parameters and pigments of Aloe vera $\mathrm{L}$. Plant Physiol. Biochem. 2016, 106, 141-148. [CrossRef] [PubMed]

63. Gorbe, E.; Calatayud, A. Applications of chlorophyll fluorescence imaging technique in horticultural research: A review. Sci. Hortic. 2012, 138, 24-35. [CrossRef]

64. Calatayud, A.; Roca, D.; Martínez, P.F. Spatial-temporal variations in rose leaves under water stress conditions studied by chlorophyll fluorescence imaging. Plant Physiol. Biochem. 2006, 44, 564-573. [CrossRef]

65. Fu, W.; Li, P.; Wu, Y. Effects of different light intensities on chlorophyll fluorescence characteristics and yield in lettuce. Sci. Hortic. 2012, 135, 45-51. [CrossRef]

66. Baker, N.R.; Rosenqvist, E. Applications of chlorophyll fluorescence can improve crop production strategies: An examination of future possibilities. J. Exp. Bot. 2004, 55, 1607-1621. [CrossRef] [PubMed]

67. Ahmad, I.; Dai, H.; Zheng, W.; Cao, F.; Zhang, G.; Sun, D.; Wu, F. Genotypic differences in physiological characteristics in the tolerance to drought and salinity combined stress between Tibetan wild and cultivated barley. Plant Physiol. Biochem 2013, 63, 49-60. [CrossRef] [PubMed]

68. Khalili, M.; Pour-Aboughadareh, A.R.; Naghavi, M.R.; Mohammad Amini, E. Evaluation of drought tolerance in safflower genotypes based on drought tolerance indices. Not. Bot. Horti Agrobot. 2014, 42, $214-218$. [CrossRef]

69. Naghavi, M.R.; Pour-Aboughadareh, A.; Khalili, M. Evaluation of drought tolerance indices for screening some of corn (Zea mays L.) cultivars under environmental conditions. Not. Sci. Biol. 2013, 5, 388-393. [CrossRef]

70. Pour-Siahbidi, M.M.; Pour-Aboughadareh, A. Evaluation of grain yield and repeatability of drought tolerance in-dices for screening chickpea (Cicer aritinum L.) genotypes under rainfed conditions. Iran. J. Genet. Plant Breed. 2015, 2, 28-37. 
71. Khalili, M.; Pour-Aboughadareh, A.; Naghavi, M.R. Assessment of drought tolerance in barley: Integrated selection criterion and drought tolerance indices. Environ. Exp. Biol. 2016, 14, 33-41. [CrossRef]

72. Etminan, A.; Pour-Aboughadareh, A.; Mohammadi, R.; Shoshtari, L.; Yousefiazarkhanian, M.; Moradkhani, H. Determining the best drought tolerance indices using artificial neural network (ANN): Insight into application of intelligent agriculture in agronomy and plant breeding. Cereal Res. Commun. 2019, 47, 170-181. [CrossRef] 